\title{
Simple but tricky: Investigations of terephthalic acid purity obtained from mixed-PET waste
}

\author{
Lelia Cosimbescu*, Daniel R. Merkel, Jens T. Darsell, Gayaneh Petrossian \\ Pacific Northwest National Laboratory, 908 Battelle Blvd., Richland, WA 99354, USA \\ lelia.cosimbescu@pnnl.gov
}

Supplementary Information

\section{Methods}

General

All chemical manipulations were performed using standard organic chemistry techniques under a nitrogen atmosphere. Sodium hydroxide, ethylene glycol, ethanol 200 grade, concentrated hydrochloric acid were purchased from Aldrich and used as received. Technical grade ethanol was acquired from Acros Organics. Mixed color bottles made of PET were obtained from a local recycling receptacle, rinsed with tap water, and dried. For most experiments, the PET bottles were chopped without removing labels, adhesives and polypropylene rings to probe for the tolerance of the process to impurities and evaluate purity of the subsequent product. Materials originating from this process are hereon referred to as "mixed-waste". In one instance, the bottles were stripped of labels and all other plastics, and the adhesive was briefly wiped with hexanes. No additional cleaning was involved in the preparation of the PET bottles.

PET chopping and particle size assessment

PET bottles were reduced to chips by mechanical chopping in a Battenfeld Gloucester Engineering Company, Inc. model 685 horsepower pelletizer. Particle size distribution was evaluated according to the relevant portions of ASTM Standard D1921.

Characterization of reaction products 
Nuclear magnetic resonance (NMR) spectra were obtained with an Agilent-Oxford (Santa Clara, CA, USA) $500 \mathrm{MHz}$ spectrometer at $499.8 \mathrm{MHz}\left({ }^{1} \mathrm{H}\right)$ and $125.7 \mathrm{MHz}\left({ }^{13} \mathrm{C}\right)$. The chemical shifts are reported in delta $(\delta)$ units, parts per million $(\mathrm{ppm})$ referenced against DMSO-d6, in which the samples were prepared.

DSC measurements were performed on a Q2000 calorimeter (TA Instruments, New Castle, DE, USA). Samples weighing 7 to $9 \mathrm{mg}$ were first heated from $25^{\circ} \mathrm{C}$ to $350{ }^{\circ} \mathrm{C}$, then cooled to $25^{\circ} \mathrm{C}$ and then heated back up to $350^{\circ} \mathrm{C}$; the samples were held at each temperature for $5 \mathrm{~min}$. The linear heating and cooling rate was $5^{\circ} \mathrm{C} / \mathrm{min}$ and the DSC cell was purged with nitrogen during each analysis. Temperature information for peaks and enthalpy changes $(\Delta H)$ for respective transformations were obtained using the TA Universal Analysis software.

\section{Powder Xray Diffraction}

Powder X-ray diffraction was performed using a Rigaku Miniflex II (Rigaku, Tokyo Japan) x-ray diffraction system utilizing $\mathrm{CuK} \alpha \mathrm{x}$-ray radiation at a wavelength of $1.5406 \AA$. The resulting diffraction pattern was analyzed with PDXL2 analysis software (Rigaku) and phases identified using ICDD 2020 PDF4+ database (International Center for Diffraction Data, Newtown Square PA, USA). The diffraction pattern for the materials presented here was found to match PDF (powder diffraction card file) number 00-031-1916 for terephthalic acid with triclinic crystal structure (space group P-2)). No additional peaks to suggest monoclinic phase were found.

NMR Data: 


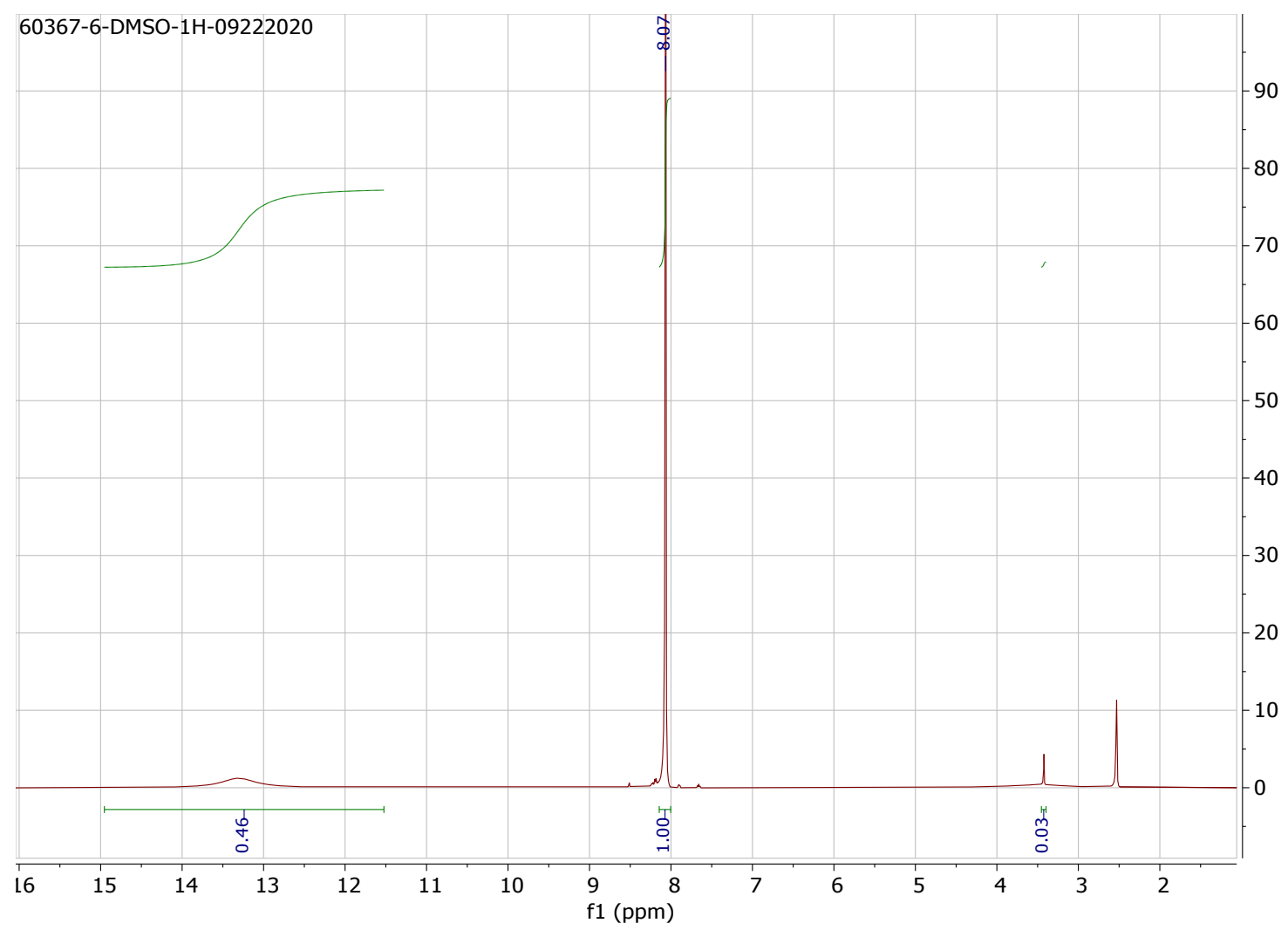

Figure S1: ${ }^{1} \mathrm{HNMR}$ of TPA1

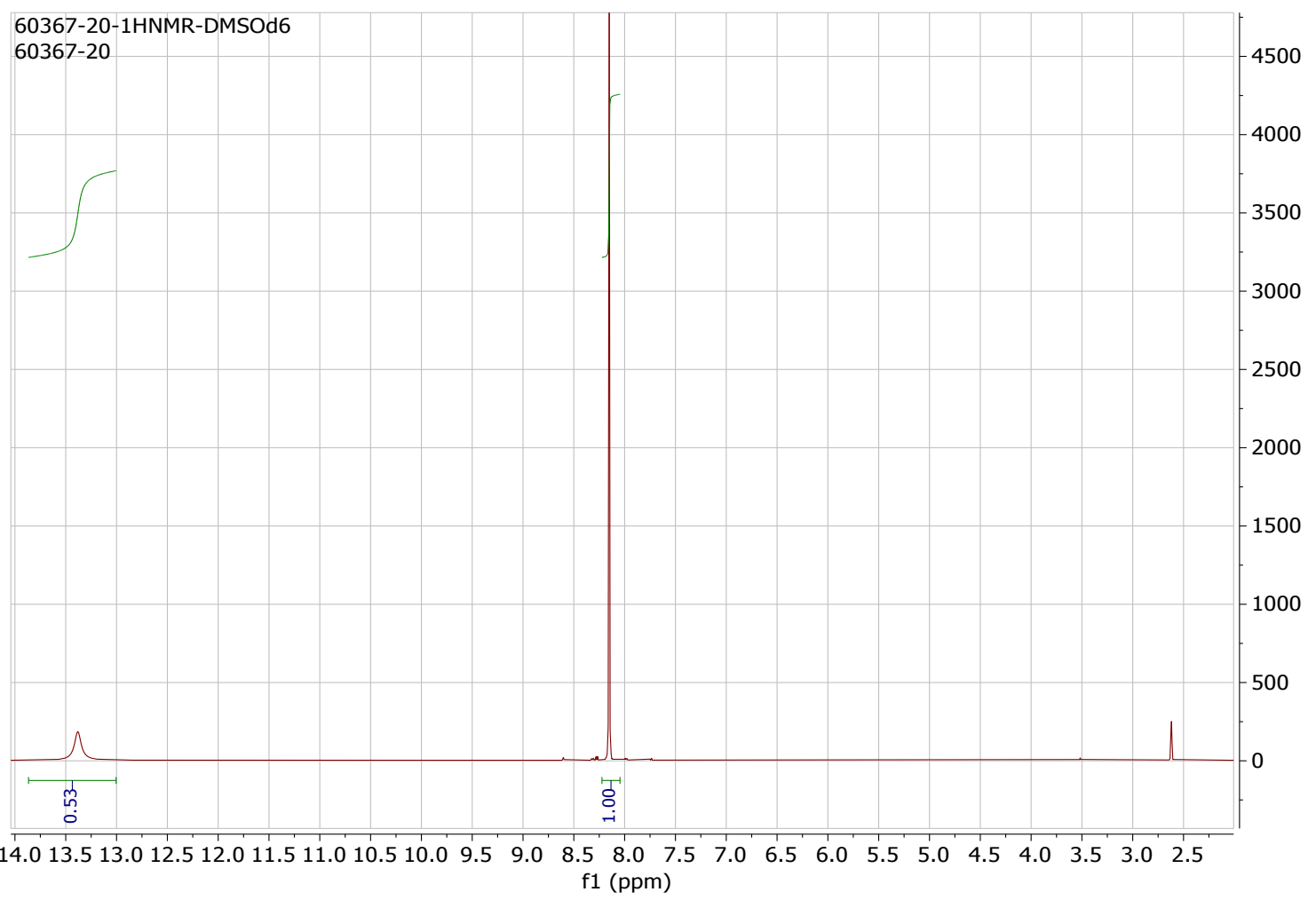


Figure S2: ${ }^{1} \mathrm{HNMR}$ of TPA2

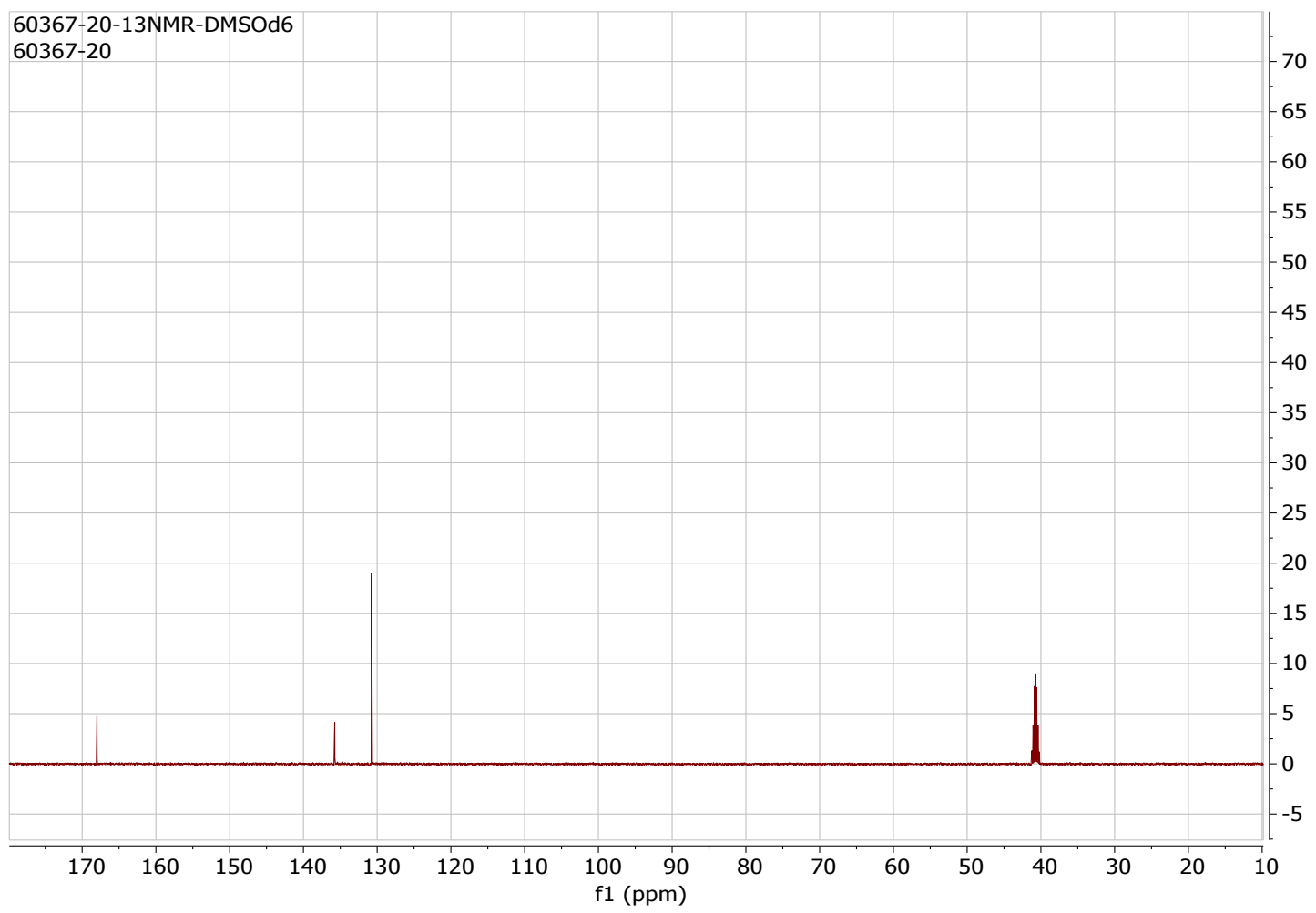

Figure S3: ${ }^{13} \mathrm{CNMR}$ of TPA2

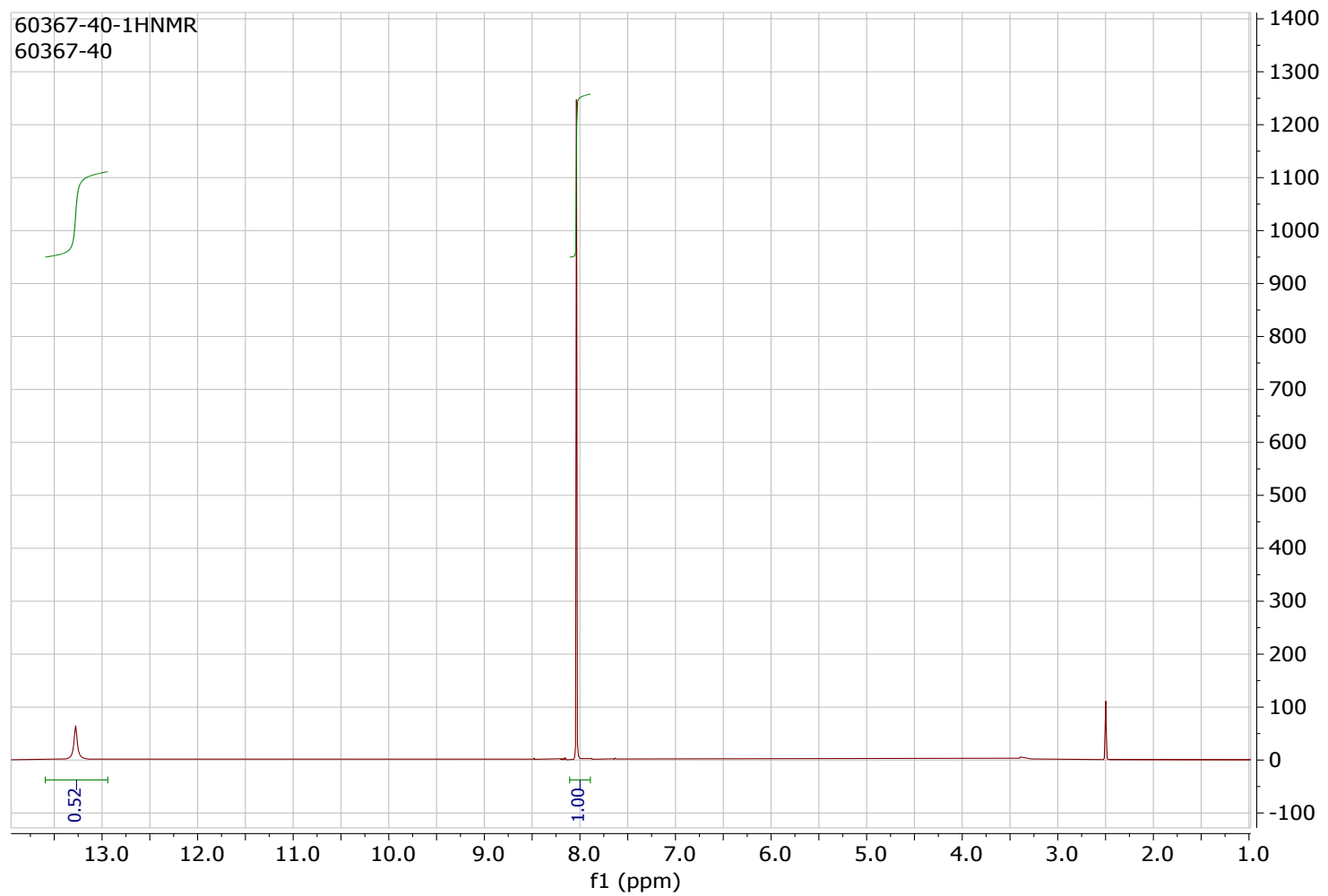


Figure S4: ${ }^{1} \mathrm{HNMR}$ of TPA3

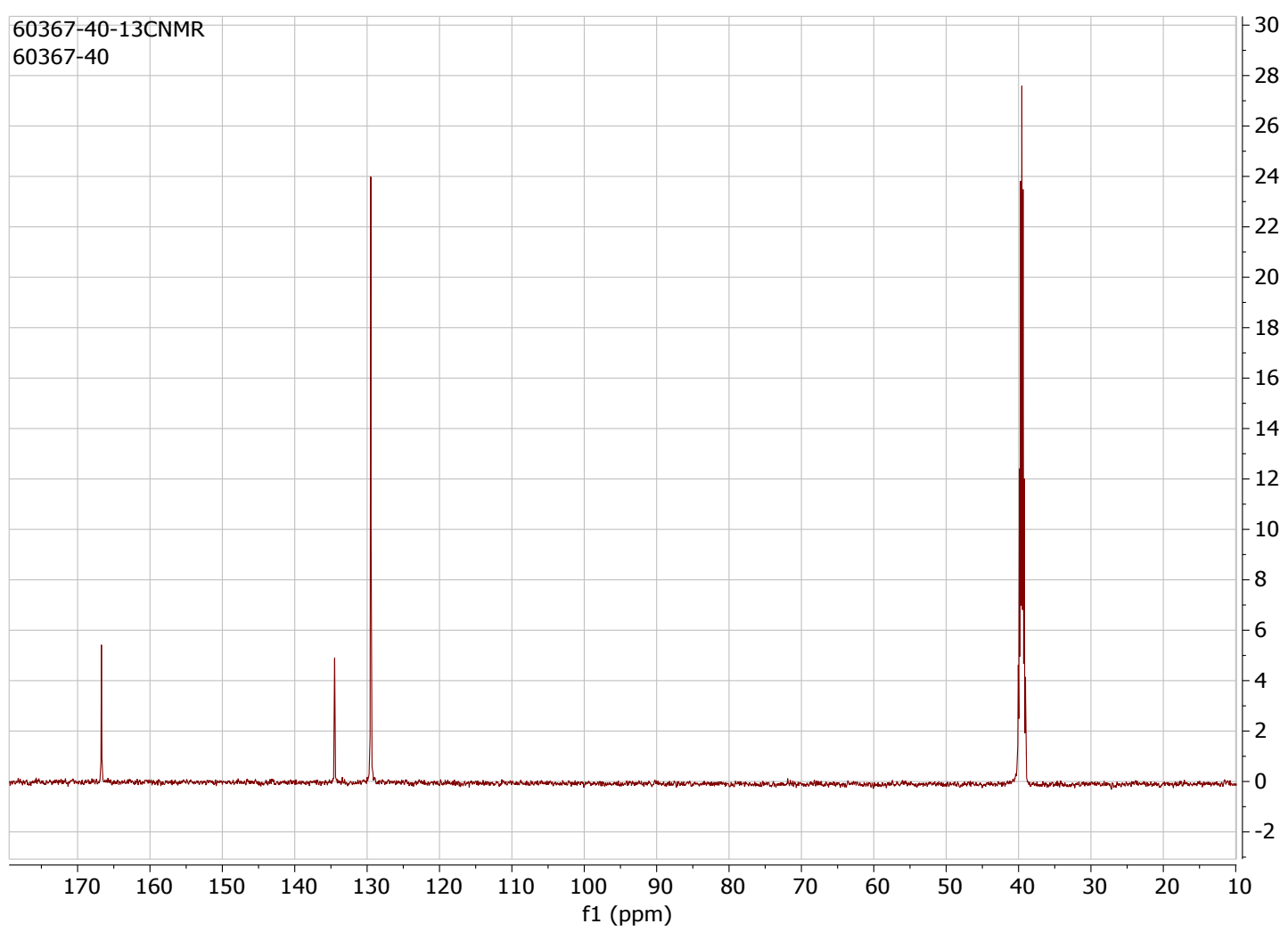

Figure S5: ${ }^{13} \mathrm{CNMR}$ of TPA3 


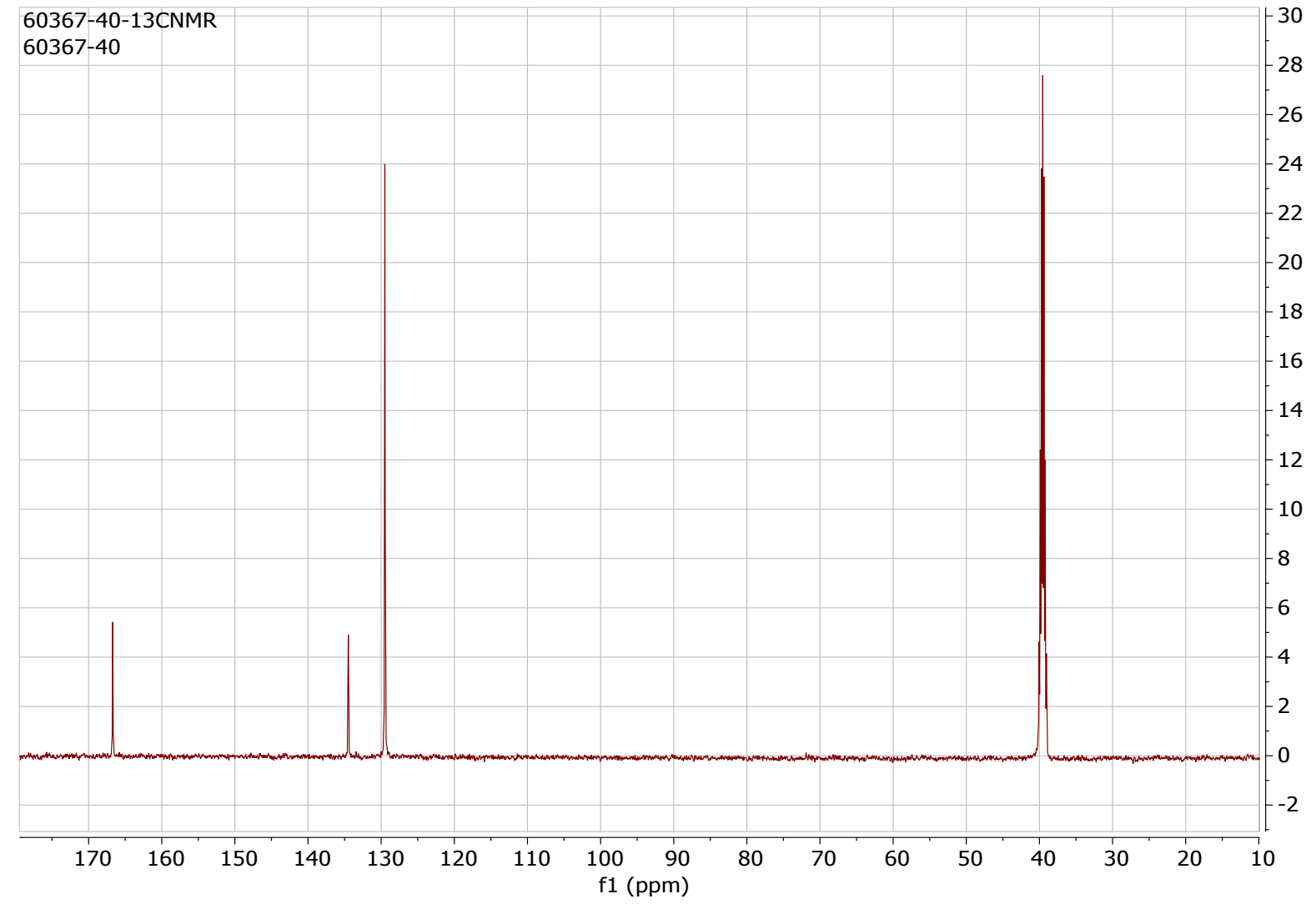

Figure S6: ${ }^{1} \mathrm{HNMR}$ of TPA4

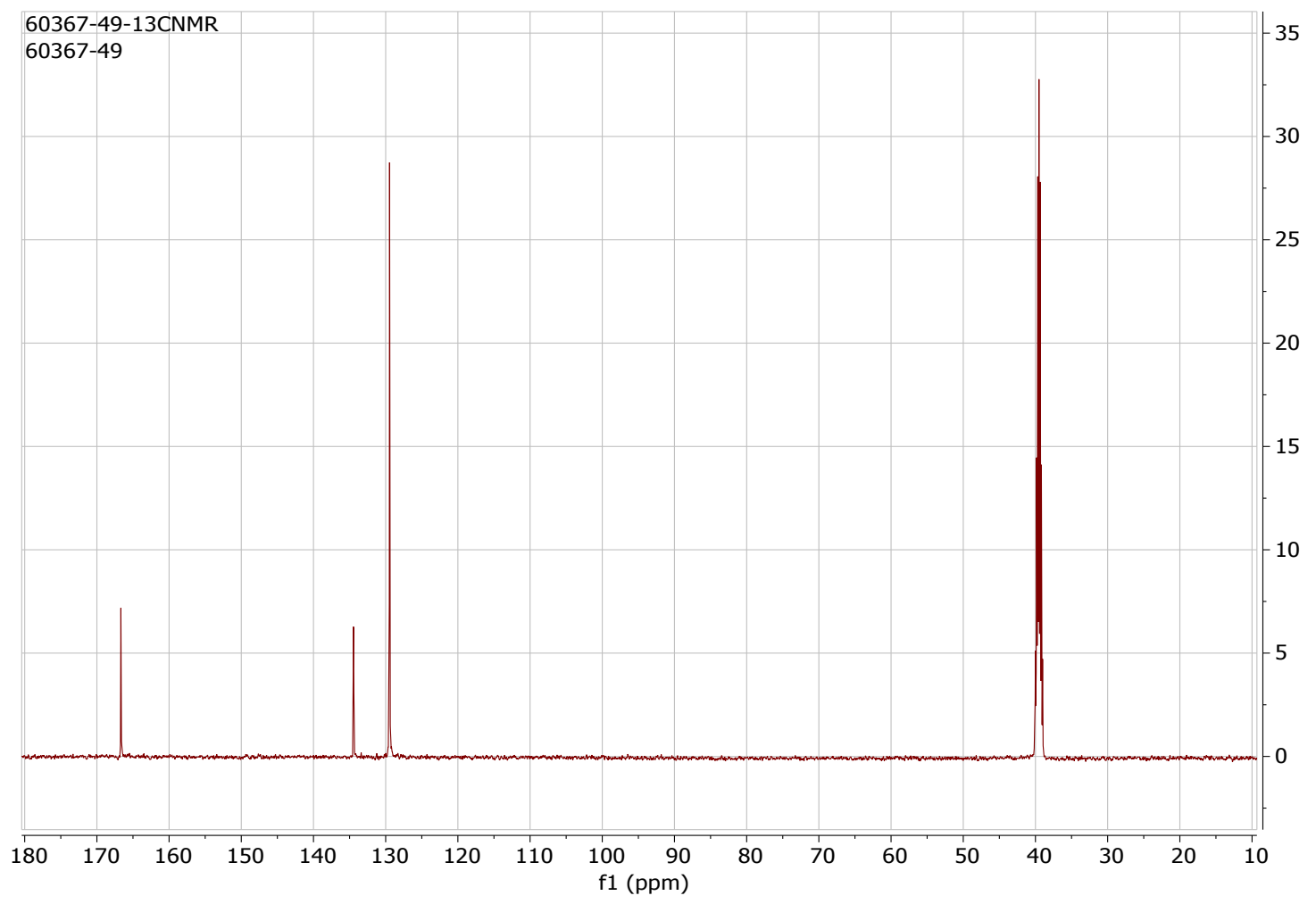


Figure S7: ${ }^{13} \mathrm{CNMR}$ of TPA4

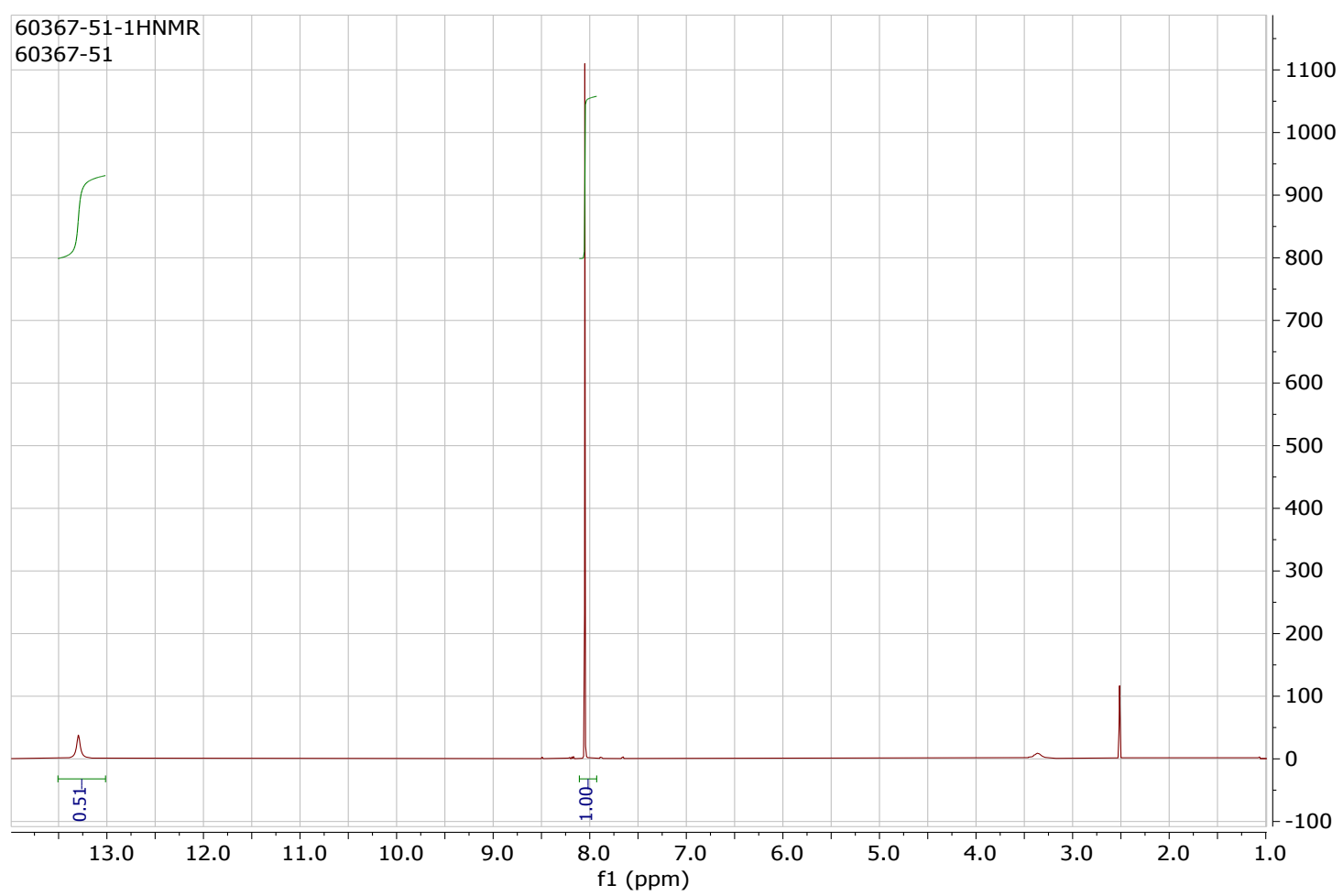

Figure S8: ${ }^{1} \mathrm{HNMR}$ of TPA5

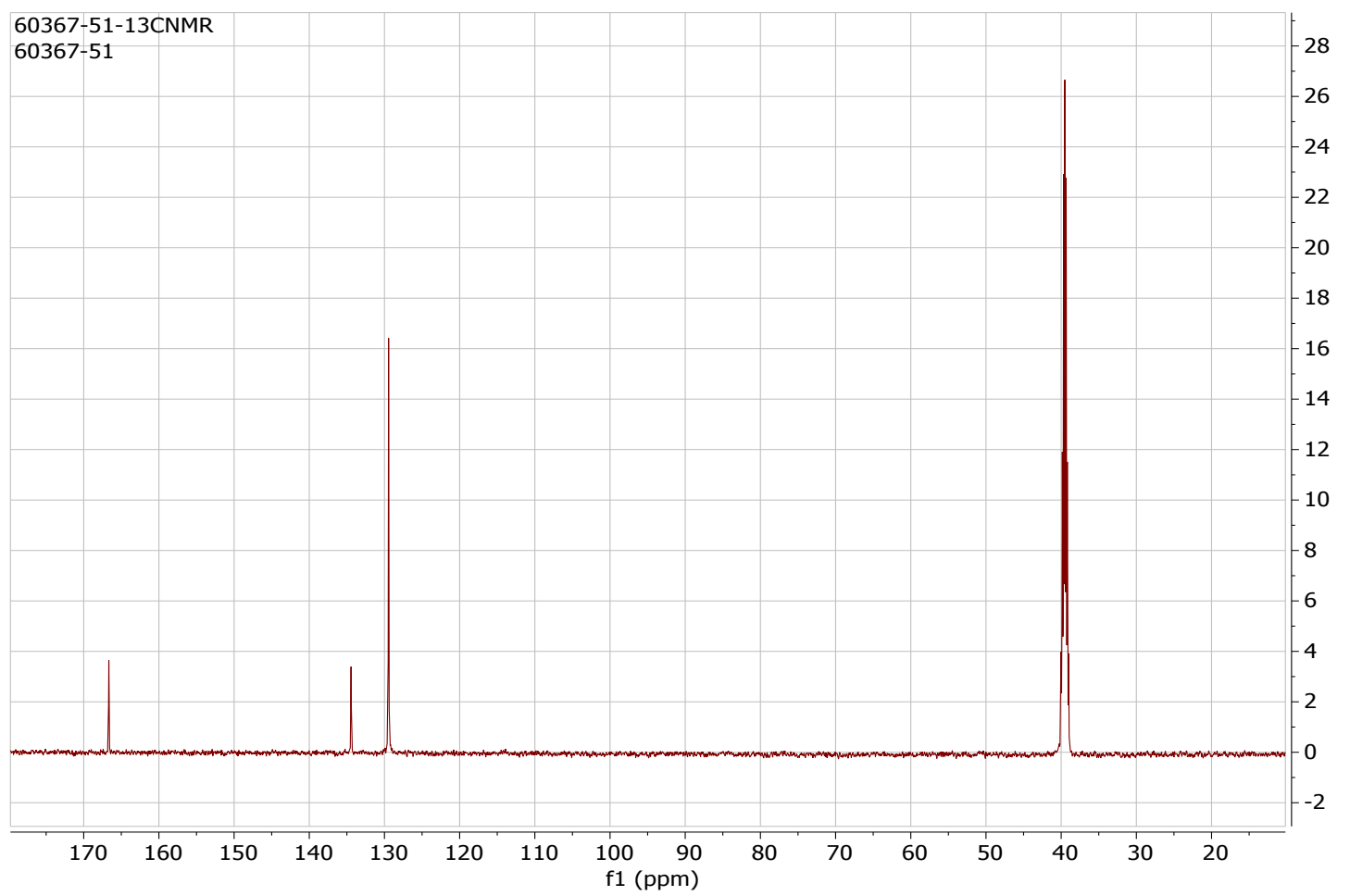

Figure S9: ${ }^{1} \mathrm{HNMR}$ of TPA5 
Legend for authors' reference:

TPA1 $=60367-6$

TPA2 $=60367-20$

TPA3 $=60367-40$

TPA4 $=60367-49$

TPA5 $=60367-51$ 